\title{
Nurturing innovation and creativity in educational practice: principles for supporting faculty peer learning through campus design
}

\author{
Lewis Winks $^{1}$ (D) Nicholas Green ${ }^{2} \cdot$ Sarah Dyer $^{1}$
}

Published online: 13 November 2019

(C) The Author(s) 2019

\begin{abstract}
While much work has focused on pedagogical innovation processes within universities, less has been said of the processes and cultures which foster and give rise to creativity within higher education and the ways in which faculty members are encouraged to develop their pedagogy across disciplines and within their departments. This paper examines the ways campus spaces at a UK university are utilised by staff for peer learning and the barriers and affordances for innovation and creativity in educational practice. Utilising an interdisciplinary design, this paper suggests that the various spaces available to university teaching staff are able to be further utilised to support creative practice and peer learning, presented as four design principles: innovation happens in everyday spaces, communal spaces need social functions, forums have different scales, and collaborative spaces require a collective culture. The normalising of a culture of innovation requires both physical and behavioural adjustments to the use of space, suggesting that both faculty and institutions need to work together to reimagine spaces for faculty peer learning.
\end{abstract}

Keywords Innovation · Peer learning · Campus design · Learning communities · Communities of practice

Lewis Winks is a geographer specialising in sustainability and environmental education; Nicholas Green is a spatial designer, artist and urban designer; Sarah Dyer is a geographer with an interest in Higher Education and is director of the Exeter Education Incubator.

Lewis Winks

L.Winks@exeter.ac.uk

Geography, University of Exeter, Exeter, UK

2 Arts and Culture Fellow, University of Exeter, Exeter, UK 


\section{Introduction}

Innovation in higher education has been the focus of much debate and research for many decades, pushing the modern university to reconsider what a 'higher education' consists of, looks like, and feels like to those involved, both as learners and educators (Brennan et al., 2014; Enarson \& Drucker, 1960; Lindquist, 1974). As the decades have moved on, these debates have intensified with increasing pressure for UK higher education (HE) institutions to justify increasing fees, to widen their participation from marginal groups, and to respond to the needs of the economy and workplaces into which their graduates enter after study (Brown, 2015; Macdonald \& Stratta, 2001). The 'traditional' model of HE learning, typified by large lecture theatres and the 'sage on a stage', are now being supplemented with increasing favour being lent to dynamic workshops, student-led study, and technology-assisted learning. Some universities (such as Northampton in the UK) have made steps toward phasing out large lecture theatre learning, in favour of dialogic pedagogies and convivial spaces (CoadySchaebitz, 2016). So too, the increasing pressure of the Teaching Excellence Framework upon institutions has placed newly found concern for the 'quality' of education occurring within university departments, leading university management to invest in programmes of training and institutional incentives for updating teaching practices (Ashwin, 2017; Berger \& Wild, 2016; Gunn, 2018).

However, encouraging educational innovation is notoriously difficult. Multiple barriers exist alongside the opportunities, while the drivers are complex and uneven in their effect across institutions (Brennan et al., 2014; Klein \& Sorra, 1996). Many institutions are now supporting educational innovation using cross-departmental models which enable educators to find the space and time to pursue new ideas and interventions within their practice. In particular, the need for a community focused approach to the organisation of spaces within universities is prominent in discussion:

As recognition grows for the idea that knowledge and skills develop through, and exist on, a collective, social level and not just within the individual, university campuses will need to provide spaces that facilitate the formation of communities of common interest and enable greater communication, interaction and collaboration. (Jamieson*, 2003 p.122)

This re-prioritisation of space within the university requires a restructuring of teaching and learning to encourage collaborative, active, and student-centred approaches (as expertly highlighted by Hadgraft and Dane (2014)), yet also calls for interaction between faculty, and encourages spontaneous and serendipitous encounters(Jamieson, 2008). Such encounters are important for the co-development of members of the academic community and for developing the peer support necessary to cultivate innovation. Furthermore, Lippman et al. (2005) consider university learning spaces as consisting of 'layered transactional settings' which encourage dynamic approaches to teaching, while Jamieson (2008) comments on the faculty-faculty interaction benefits which evolve out of space planning and which place interaction and sociability of the learning community at its centre while sharing goals and developing educational practices — sometimes referred to as a 'community of practice'.

Learning communities and communities of practice are postulated as frameworks for collaborative working which are applicable to innovation and link with the ways in which innovation is seen to be successful (Wenger, 1998; Wenger, McDermott, \& Snyder, 2002). Specifically, connecting with observations that innovation requires support and encouragement 
from colleagues, as well as management (Hannan and Silver, 2000). Additionally, the importance of learning communities is seen to connect with spaces of learning, as faculty connect with one another both formally and informally through creative campus design. However, the physical manifestation of the campus remains in the most part a major obstacle to communities of practice taking hold within universities (Jamieson, 2003).

Two key terms are used in this paper: innovation and creativity. Both terms have a variety of definitions and carry varying currency depending on context and audience, and so it is pertinent to provide a little definition before proceeding. Firstly, the term innovation used in this paper is forwarded as a symbol of emergent expression in the form of educational practice and is seen by the authors very much as a relational process rather than outcome. We resist mechanistic and deterministic connotations of the word, and so too, we look further than the metric-bound notion of innovation. Secondly, the term creativity is deployed in this paper as both a precursor and outcome of the process of innovation. We see creative spontaneity as an essential ingredient for new educational practices - emerging from practitioner spaces, places, and routines. Magdaniel (2016) is helpful here and considers these terms in a technology context: '[We] can relate innovation to creativity through the processes of knowledge creation, diffusion and its further application to develop new and improved technologies because these processes involve people and their ideas. Although there is a clear link between these two terms, innovation has gained more attention than creativity in some socio-economic contexts' (p.9). The creative process of innovation considered in this paper is seen through the lens of surprise and serendipity rather than plan and provision, yet is informed and contained within a structure of norms, practices, and physical space — and as Magdaniel notes, through diffusion and eventual application in a HE learning context.

This paper recognises the difficulty of working with pre-existing spaces for enabling so-called serendipitous encounters on campus as described by Metcalf 2002 in Jamieson (2008) and examines the ways in which universities might encourage further utilisation of the campus for faculty-faculty interaction and development. A variety of campus spaces are seen to be conducive to creating opportunities for peer learning and support, essential to the innovation process itself. Here, we engage with 'peer learning' as a process driven in part by serendipitous encounters and as opportunities to express pedagogical creativity. We intentionally orbit around these phrases to push the conversation toward something which is both unintentional and yet considered in this paper as antecedent to educational innovation. Following on from Beckers (2016) framework of 'Purpose-Process-Place', this paper places emphasis on the processes within place-while acknowledging purpose within the milieu of HE educational creativity and stimulating peer-learning. We make use of a cross-disciplinary methodology to examine the ways in which spaces of creativity and peer learning are utilised at Exeter ${ }^{1}$. In order to achieve this, the research is underpinned by an arts and culture fellowship which facilitated the work of an urban designer alongside geography academics-stimulating a creative approach to data collection and interpretation (outlined in detail in the methodology section of this paper). The findings are presented as a series of visual representations of campus spaces, developed from detailed participant testimony and observation. The discussion section draws out insights from this work to present opportunities which exist within university campuses for developing spaces of pedagogical creativity and peer learning.

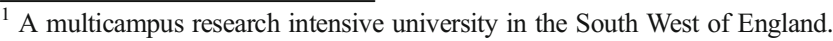




\section{Materials and methods}

The methods which give rise to the findings presented in this paper and the data which underpins them are developed from the work of urban designers, architects, and artists. Their methodologies include the following: numerous site visits, photographs of public spaces, mapping of physical and built features, as well as patterns observed in the way people use the space. Such approaches promote immersion in the area of study, in an attempt to cover as much ground as possible.

\section{Deep observation}

The American writer and urban activist, Jane Jacobs, has previously argued that a sense of place and identity is formed through repeat encounters, passive surveillance (or 'eyes on the street' as she terms it), and the interdependencies between different street users (Jacobs, 1961). Using journalistic flair, Jacobs turned everyday situations into integral components of what we understand as our community. This work also makes use of the extensive and deep observation methods utilised by Georges Perec, who in one literary experiment attempted to exhaustively observe a site in Paris over the course of 3 days. His inevitable failure caused him to reflected on the subjectivity of our observations of others behaviour and of static and moving features within an environment (Perec, 2010).

Danish architect Jan Gehl published, Life Between Buildings in 1971, the first of many works which promote a 'human-scaled' design of spaces based upon careful observational studies (Gehl, 2011). Gehl along with his team devised methods to map and record behaviours in public spaces, attempting to develop new metrics for achieving a human-scale design approach. Gehl's Life Between Buildings, and subsequent publications (Gehl, 2013; Gehl \& Gemzøe, 2004; Gehl \& Svarre, 2013) introduced their own design guides based upon firsthand research, as well as a methodology for others to conclude upon their own design principles relevant to the context they are working within.

\section{Exploring, mapping, and drawing spaces in the university}

Setting out to explore the spaces on the university campus, particularly interior spaces frequented by the routines of academics and professional service staff, posed a challenge to this cherished approach for establishing an understanding of a study site, namely access.

A collaborative approach was made use of to establish meaningful access to the spaces used by academics and professional service staff, involving three co-researchers and two university support staff responsible for facilitating the arts and culture collaboration. A series of in-depth interviews were arranged across a 3-week period with twelve academic staff from all six academic colleges and across two campuses. These staff were already engaged with pedagogic innovation within the university (through the University of Exeter Education Incubator ${ }^{2}$ ) which provided access to staff working in different departments and locations across the university (see Fig. 1 for a breakdown of how colleges were represented by this work).

\footnotetext{
${ }^{2}$ The University of Exeter's Education Incubator was created in 2017 to encourage and support pedagogic innovation across the university, providing financial support for 'incubator fellows' to develop projects (see: Dyer, 2018).
} 
Academic Colleges

- 3 participants from College of Life and Environmental Sciences (2 departments)

- 3 participants from Business School (3 departments)

- 1 participant from College of Engineering, Mathematics and Physical Sciences

- 2 participants from College of Medicine and Health (1 department)

- 1 participant from College of Social Sciences International Studies

- 2 participants from College of Humanities (1 department)

Fig. 1 Representation of colleges within this research

Interviews with each participant centred on a workbook with ten exercises. These required academics to describe their office, the department building, and a typical daily occupation of the campus, using maps and drawings (see Figs. 3 and 4 for examples). Utilising the tools and conventions of the architectural and design profession (such as the plan drawing or the site plan) led to a series of discussions about the representation of features which may have been taken as a given or overlooked. The difficulty in describing the subtleties and nuances of the everyday work environment through these drawings proved a catalyst for richer verbal descriptions of space than what may have otherwise been the case in a purely verbal interview.

The extended description of academics' experiences on campus obtained through the interviews was important in attempting to establish an equivalent body of qualitative data about usage that one is able to accumulate purely through observation during frequent site visits to a public space. As it is difficult to directly observe academics' patterns of use, these were instead recorded through the stories and information recounted in the discussion and drawing exercises (see Fig. 3).

As the majority of interviews were conducted in the offices of the academics, access in a practical sense was granted both into this space, as well as the department building itself. These meetings were also used as an opportunity to photograph the communal and shared spaces between offices where important moments of contact between colleagues occur (see Fig. 6). Directly following the interviews, it was possible to visit locations described and document these first-hand to supplement the verbal and pictorial descriptions.

\section{Analytical approach}

A full review of the transcripts as well as the drawn materials produced during the interview was undertaken. Listening back to the conversations and reading through the transcripts, recurring themes and pertinent responses were identified and organised under specific topics and themes. Drawn materials produced as part of the interview process, including sketches of academic's office spaces, maps describing patterns of use on campus, typical term-time, and out-of-term working schedules, were also reviewed and collated (see Figs. 2, 3, and 4). Following on from this process, architectural drawings were produced which attempt to describe the points raised in the interviews and enable reflection upon the key spatial and environmental features at play in both the challenges to and successful moments of collaboration between academic peers described (see Figs. 5, 6, and 7). These drawings were reviewed and discussed between participants, and subsequently, a series of design principles were developed reflecting the information gathered in these multiple forms and iterations.

The images presented in the following section follow on from this immersive and detailed methodology, underpinned by interview and observational data. This approach has been chosen in order to more creatively represent the use of these spaces, while also enabling a cross-disciplinary approach to higher education research. The authors hope that while the 


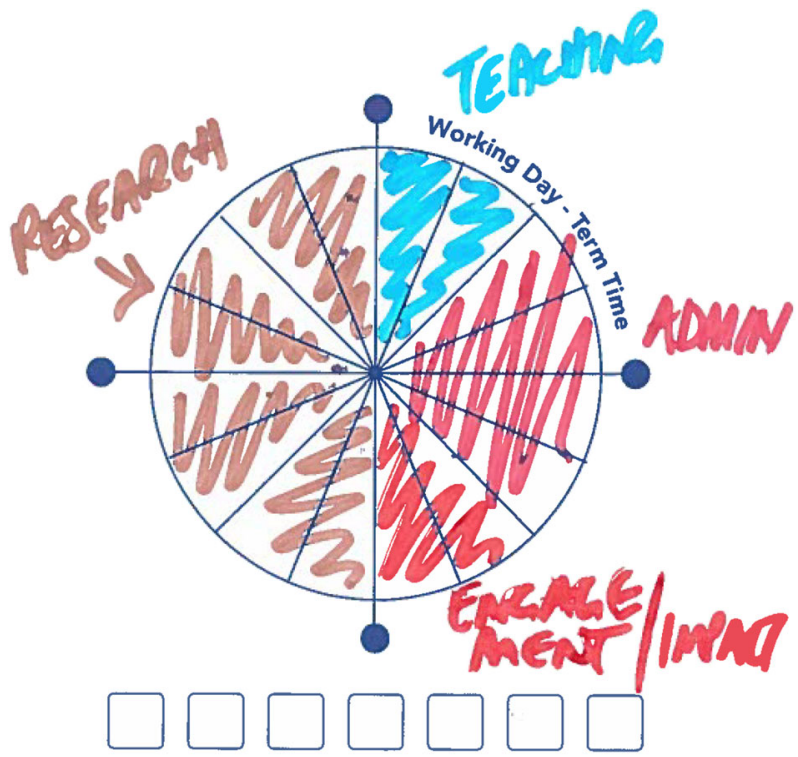

Fig. 2 Diagram showing the typical schedule of an academic working day (participant generated)

findings will be of interest to readers, so too will the innovative methodology deployed to collect this data.

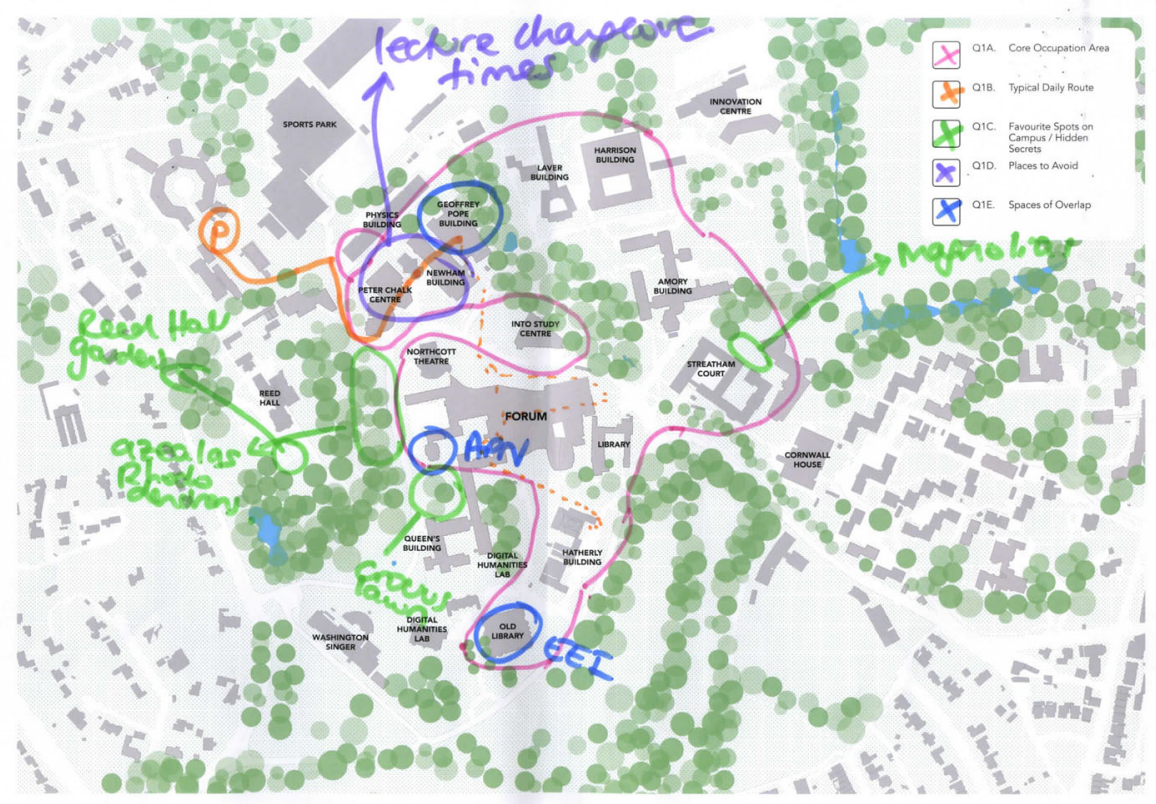

Fig. 3 Map from participant showing occupation of the campus, favourite places, and places to avoid and spaces of overlap between colleagues 


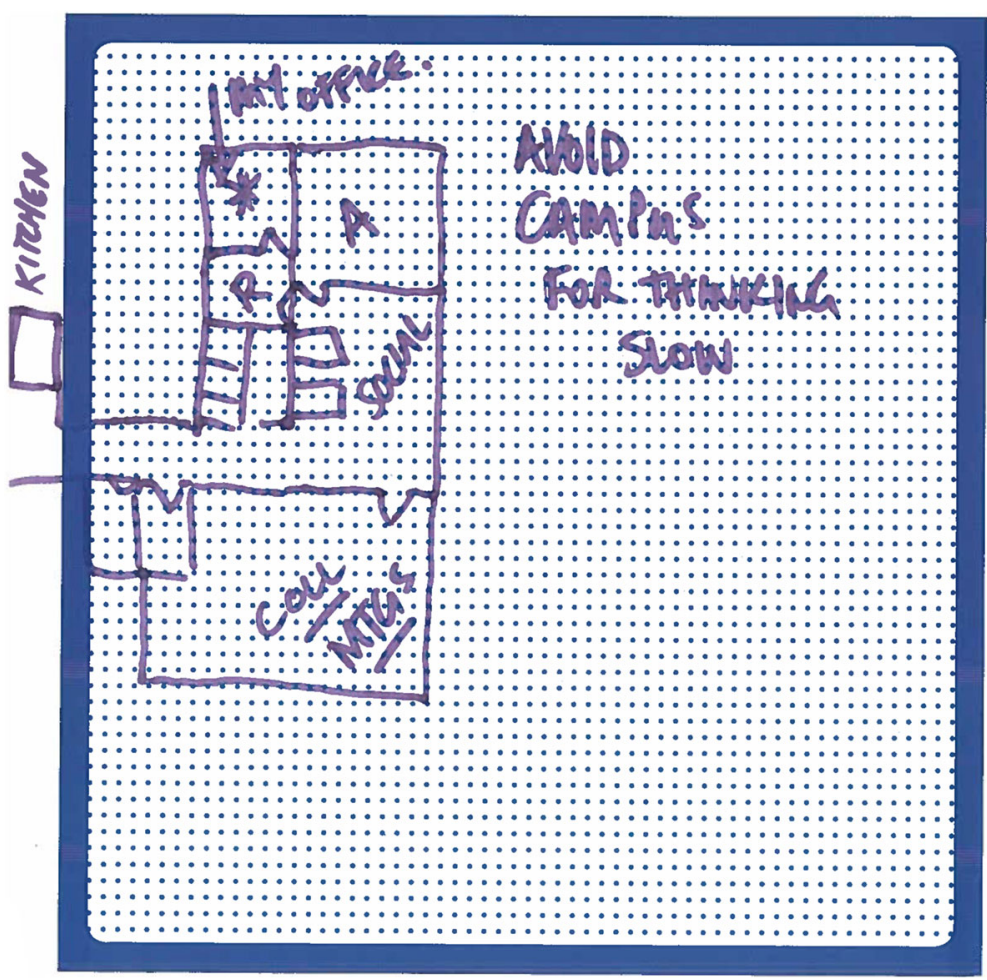

Fig. 4 Participant's sketch of office and thresholds with communal space

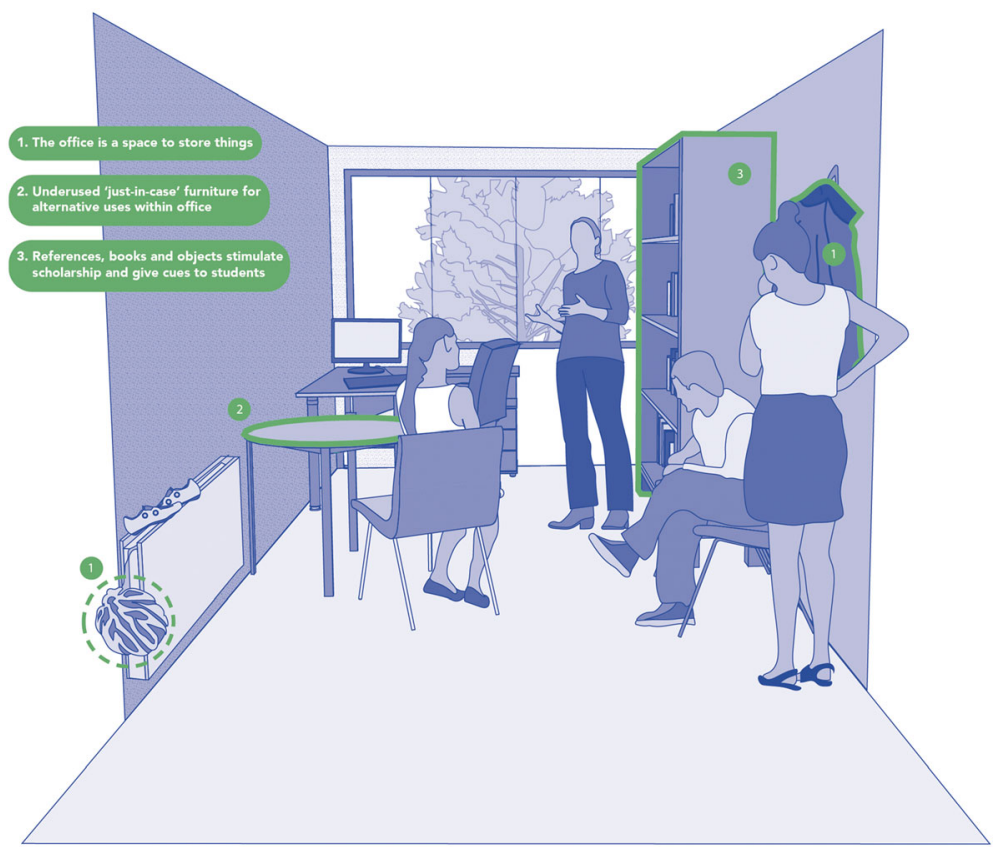

Fig. 5 A representation of an academic office space with observations noted and labelled 


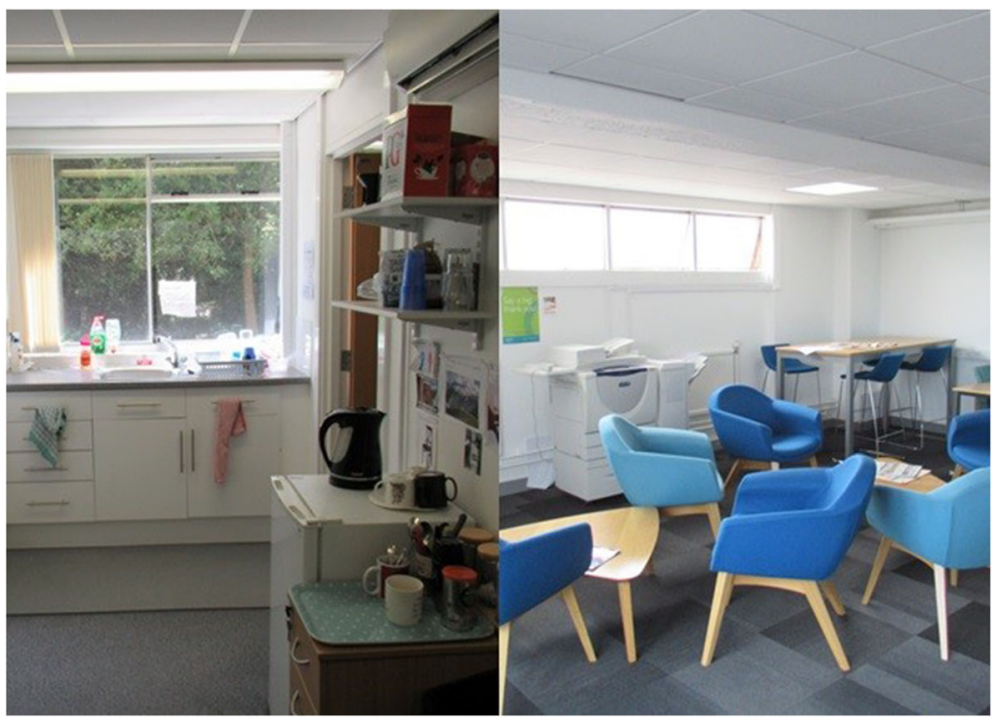

Fig. 6 Photographs of a staff kitchenette and common room space

\section{Results}

\section{Representation of spaces}

As described in the previous section, the images presented here emerge from rich description, deep observation, and discussions with participants. A selection of participant commentary is included alongside the visual presentation which follows. Building upon the intentions of the urban designers and thinkers who pioneered this approach, the portrayal of the use of university space using map and drawings elicited a series of design principles which arise from the data. These design principles are explored in the next section.

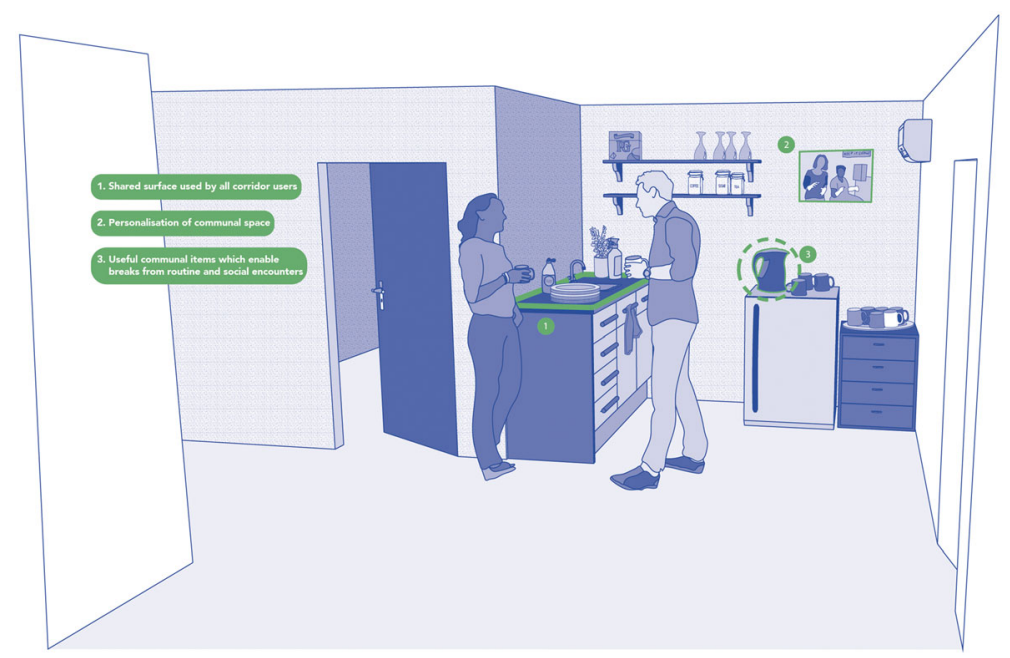

Fig. 7 A representation of a department kitchenette, with observations noted 
Emerging from the interviews with participants, four distinct campus spaces are discussed, which are explored in this section in relation to their ability to activate innovation: offices, 'everyday' communal spaces, forums and gathering spaces, and spaces conducive to collaboration.

\section{Offices}

Offices were discussed by participants in relation to their interaction with colleagues and students. Some respondents commented on the benefits of shared offices for developing working relationships with colleagues:

[Discussion about teaching practice] happens in the offices. We wander in and out of offices. Some people may say that would be really noisy and distracting, but actually it is quite a nice, open, welcoming environment where people don't feel like they can't come in. It's not a 'do not disturb' kind of set up.

Respondent from Campus $B$

Others commented that shared space can be distracting and limit their ability to concentrateand importantly - the confidentiality which private office space affords to student-faculty interactions:

We all struggle to speak to our students, our students don't want to sit in an open office and tell us their personal stories.

Respondent from Campus $B$

Alternatively, one participant suggested that a shared office offered a collaborative learning space in which students and staff could exchange ideas:

For me, how you host a space is really important, because I want my students to feel that this space is a space they can come to, to talk and explore ideas together. So, I use this a lot [pointing to a whiteboard], we'll jump up and make sense of their learning via that, or it's that counselling/coaching sort of space.

Respondent from Campus A

In this view, the office is a teaching as well as a private study space. Although there is a degree of tension between the office space as private, and as an open space of collaboration and dialogue (and occasional interruption), the importance of this space for innovation cannot be overlooked. However, it is how the office is utilised as a space of faculty-faculty as well as student-faculty interaction in conjunction with other open communal spaces which is important when considering how campus design reflects the affordances available for educational innovation.

Communal spaces

Corridors were especially noted by many of the participants as being significant sites of interaction with colleagues. They appeared in conversations as spaces which facilitate unplanned meetings and exchanges:

For me, quite a lot happens in corridors... I would always prefer to talk to someone than to write them an email first or pick up the phone, so I tend to see if I can catch someone when they are in, or say "are you around today", something like that. It is a bit more spontaneous.

Respondent from Campus A 
Corridor conversation is a lot more productive and we do it spontaneously and not necessarily ticking a box, but they tend to be quite helpful [...] the conversation is never lengthy. We are all either aware of the other human beings in the other offices, or we're aware of the time pressures. All of us. Sometimes some interesting ideas are picked up in conversation and you will go to the office and have a proper conversation and probably draw down plans to do something.

Respondent from Campus $A$

\section{Forums and gathering spaces}

While typically forums on university campuses constitute large-scale gathering spaces, sometimes with a commercial nature including coffee shops and food outlets, participants in this study noted the variety of so-called forums which exist on campus: from the small-scale (staff common rooms and kitchenettes) to the large-scale (such as open plazas and precincts). The importance of these spaces for innovation is not only the way they provide space individually but also the way they connect and interact.

The largest spaces were of importance to participants and carried with them a specific set of functions only available in traditional forum spaces:

I think there are much more big events that I have observed happening (at the Forum ${ }^{3}$ ). Before it was quite scattered, so if the University had an event you would not know where it is, and you don't see them. But now because there is a concentration point, so you feel - oh, something is happening. Even if you go to grab a book from the library, you see it.

\section{Respondent from Campus A}

However, participants also noted the importance of the smaller spaces, where otherwise mundane tasks were carried out (such as preparation of food) for interaction with colleagues:

I do go to the kitchen, a lot, to pick up hot water, to make a coffee, to warm up my lunch but the kitchen is tiny. But I have a lot of interesting conversations when I am microwaving my food and other people are waiting there for their food... While you are waiting for a cup of tea, or while you warm up your food, it is the perfect time to socialise, you can talk about anything. You meet the Director of Research there, you meet the Head of Department there...

Respondent from Campus A

For some, the large forum space was not focused on the needs and activities of staff:

I personally feel as though it's (the Forum) positioned as though it's for students, it's been designed for students, it has the Guild there, and the Library is there. A lot of student activities happen there.

\section{Respondent from Campus $A$}

I'll just go (to the Forum), grab, and come back [...] because there are too many students.

Too much complication.

Respondent from Campus A

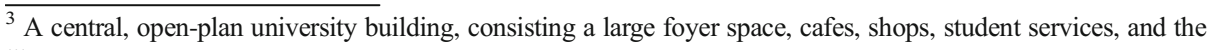
library. 
It is clear that the outdoor spaces are also important not only as route through but also as forum spaces beyond the built environment of the campus, noted for their ability to support staff in their thinking and practice:

Sometimes in the summer when I've got a bit more creative work, or there is not some much pressure on, I will walk around the whole campus and try to go to places I don't normally go.

\section{Respondent from Campus A}

[pointing at the map] I think probably this route up the hill this way is not as quick as some of the others but I like that on the way in and on the way out, it feels like I am getting some kind of breathing space. It is typically not very well used, you don't see very many people coming up or down there, and so it feels like you are getting a moment of decompression as you are coming in or out - similar to breathing in and out. Respondent from Campus $A$

\section{Spaces conducive to collaboration}

While many of the forum spaces provided on campus were seen to be student-focused, participants noted that they often looked elsewhere for support for their education work and made use of spaces more conducive to faculty-faculty interactions. Of these, offices were once again mentioned as a place for peer support:

We do speak continually. The good thing about it being quite open plan, this door here (pointing to drawing of the office) is usually kept open and people will just wander in and wander out and you chat about things. I think ... we are quite a close-knit network of people and we are constantly telling people about what we are doing.

Respondent from Campus B

Once again, corridors were mentioned by multiple participants as being spaces conducive to collaboration and 'informal meetings':

Lots of our informal meetings happen in the corridor here; we moan about things together and we discuss issues together, so the corridor over here is fantastic. And then if you move downwards, you have colleagues from other language units... it's nice to occasionally have a conversation about various issues.

\section{Respondent from Campus A}

In sum, the multiple and overlapping interactions experienced daily by participants were the result of a variety of intersecting gathering and connective spaces, both indoors and out. Collaboration was facilitated, as well as inhibited, by some of these spaces - often with overlooked and 'everyday' spaces, such as corridors and cafes, being those which most enabled faculty-faculty interaction. These informal meetings occurring across the campus individually make up a small part of the working day of education staff, yet the multi-spatial and overlapping nature of many of these interactions contribute to a culture of collaboration and innovation. Before moving into discussion, it should be noted that the extent to which this culture is nurtured and maintained is, however, also influenced by a variety of pressures and interests within, and external to, the university structure, including the following: pressure on financial resources and funding, widening student participation, advances in educational technology, and tensions between creativity and curricula prescription. These intersecting 
pressures and tensions are shaping the processes and places of learning in HE institutions (Beckers, 2016; Coulson et al., 2017).

\section{Discussion}

\section{Nurturing innovation: design principles}

This section moves on to discuss the design principles which emerge from the previously presented observational data. These design principles are discussed here as opportunities emerging for both structural changes within the university (as perhaps actioned by estates and buildings approaches) and faculty-led changes to the functioning and affordances available within these spaces. The discussion centres on cultures of creativity and peer-learning at the university campus and enables insight into the possibilities which exist for further nurturing educational innovation by focusing on spaces of interaction. This section charts the ways in which innovation emerges from everyday spaces at a variety of scales. It focuses on the social aspects of these spaces as well as the function of more 'private' spaces such as offices. Finally, the discussion considers how such spaces support communities of practice and give rise to creativity. Each of the four design principles presented here is first discussed with reference to the literature, before moving on to consider the implications and suggestions for institutional as well as individual practices.

\section{Innovation happens in everyday spaces}

Innovations within academics' teaching practice are partly borne out of the conversations, meetings, and research which take place in the everyday spaces on the university campus, including offices, corridors, meeting rooms, and communal areas. This point relates to the aforementioned 'serendipitous encounters' and their importance for informal networking, collaboration, and interaction between faculties (Metcalf, 2002 in Jamieson, 2008). The notion that pedagogical development occurs within both the formal spaces of the working environment and the everyday spaces, speaks to Lippman et al.'s (2005) 'layered transactions' within the learning environment, as overlap becomes conducive to interdisciplinary ways of working and the discovery and development of new routines. Seen in such a way, the conversations and interactions occurring in these spaces become mutually supportive and part of a 'tapestry of interaction' across the university campus.

Participants acknowledged that incremental innovations and small improvements in teaching practice are generated while educators are teaching. It follows that the spaces used to prepare and coordinate this work impact upon innovation and the potential to develop new ideas. Much of this preparation work occurs within academic offices, yet participants suggested that communal spaces were also significant in enabling effective design of teaching materials as well, while meetings arranged in social settings such as cafés and corridors and communal spaces provide opportunities to have short conversations to ask questions, to seek advice, or to plan for longer meetings in another setting. One insight which emerges, therefore, is to give greater emphasis to spaces of interaction and communication - in line with previous assertions of the importance of support from colleagues (Gosling \& Hannan, 2007; Hannan \& Silver, 2000). Communal spaces such as corridors and meeting rooms are construed then as more than simply spaces of differentiated work; they are also spaces of interaction, community, and peer support. 


\section{Communal spaces need social functions}

Related to the previous principle, shared spaces also require practical functions around which people are able to engage with one-another if the space is to reach its full potential. Useful common spaces which incorporate the infrastructure of the routine day act as an attractor and a focal point for both chance encounters and planned breaks.

A suggestion here would be to integrate useful items (coffee machine, kettle, fridge, microwave, toaster, water dispenser, printer, books, journals) into existing communal spaces in order to encourage their use as a forum and to further facilitate serendipitous encounters (Fig. 8). Creating such affordances within these spaces enables prolonged social exchanges to occur in the locations of existing office infrastructure (printer, photocopier, stationery shelves).

While these observations may appear initially to constitute aesthetic niceties, they in fact place focus upon a much developed idea within HE innovation: faculty-faculty interaction, spaces of innovation arise from social space, and the forming of shared goals and agendas (Dobbins, 2009; Hannan \& Silver, 2000). This in itself is part of the peer support and sharing networks which underpin much creativity within educational practice. From this perspective, these communal spaces with their enhanced social function provide the means for academics to share ideas and informally support their peers (Dobbins, 2009; Hasanefendic, Birkholz, Horta, \& van der Sijde, 2017).

\section{Forums have different scales}

There are a number of communal areas used throughout the typical day of an academic ranging from a space with a shared kettle or microwave to common rooms and cafés. These communal areas can act as 'anchors' or focal points for the social life of those based within the office

Fig. 8 Forums and precincts exist in outdoor spaces as well

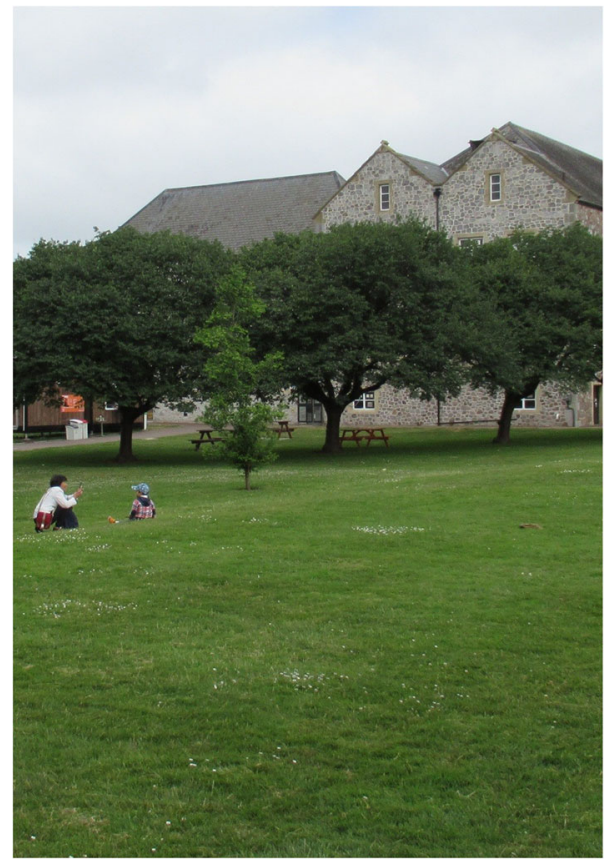


along a particular corridor, a building, or an entire area of the campus depending on their scale. The larger of these anchor spaces are sometimes referred to as forums, or precincts, and provide interaction spaces within the physical space of the university. They are often seen as central and important spaces and provide the backdrop to social time, meetings, and study. However, participants suggested that smaller and less formal spaces carry similar 'forum functions' and that these spaces are often overlooked.

Indeed, it has been noted that these spaces offer important functions for students and faculty, in the development of new pedagogical approaches, and that good campus design should reflect their importance, as well as the linkages between them (Lippman, Jamieson, \& Dane, 2005). These linkages are observed to also include important assemblages of outdoor spaces including pathways and open spaces such as lawns (see Fig. 9). Indeed, there is a growing realisation of the importance of outdoor spaces on campus for teaching and learning, as well as for developing a sense of inclusion (Aydin \& Ter, 2008; Griffith, 1994).

While the larger forums or precincts are important, smaller spaces-kitchenettes and common rooms, for example - are significant also for crossover and dialogue between faculty within and between departments (see Figs. 1 and 2). As noted by P. Jamieson (2003), these spaces have often been overlooked:

In contrast to this concept of a purpose-built learning precinct, the reality is that most universities consist of discipline-based buildings which form discrete environments within the greater campus and that have commonly been extended over time without recourse to a grand planning schema (p.124).

Clearly, there is opportunity to regard forums as existing on multiple scales, and to invest in a variety of 'anchor spaces' on the campus, envisaging them as interconnected and working together. Smaller shared spaces which are used often throughout a typical day require the least investment but can have a disproportionate impact on levels of communication amongst academics and professional services staff, because it is these forum spaces which frame

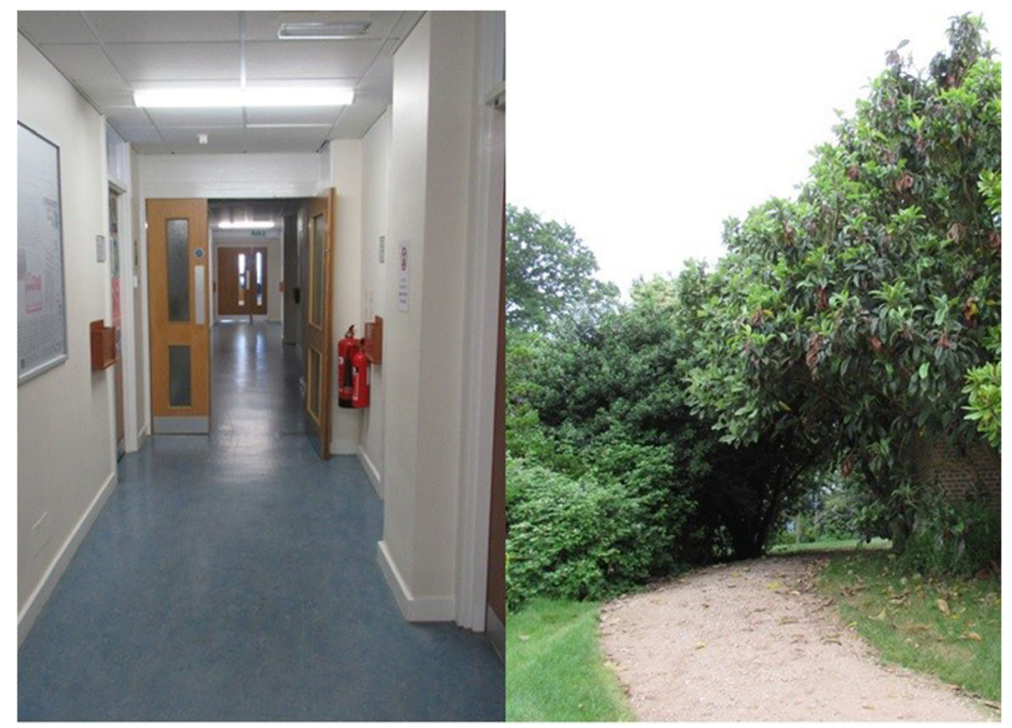

Fig. 9 Corridors and paths connect spaces as well as acting as places of cross over and layered transactions on campus 
frequent contact between colleagues. In addition, there is an opportunity here to acknowledge the way academics use communal spaces to take 'productive breaks' from work and how such communal spaces cater for 'serendipitous encounters' between educators.

\section{Collaborative spaces require a collective culture}

Finally, it is important to note that social spaces on campus are primarily made social through their patterns of use. These spaces require activation, and this in turn requires a culture which acknowledges the value of social exchange as part developing new ideas amongst academics and for maintaining well-being in the workplace. There is clear scope to make further use of common room areas for social functions and collaboration. This requires coordination and communication in order to imbed and 'normalise' these functions as an everyday practice and establish communal spaces within the institutional memory of departments.

There are clear links between this observation and the central components underpinning communities of practice. While communities of practice share goals and aspiration and work with common purpose; they also share spaces and indeed much of the practice itself stems from the use of this space. The normalizing of routines and behaviours in these spaces in order to support cultures conducive to creativity and innovation requires careful attention to be paid to the function of the space and the way in which it can support a range of collaborative activities. In many ways, this design principle points to overarching concerns regarding cultures of creativity in higher education, stemming from both structural and individual activity. Providing the means for this culture to operate across the campus and within departments is an essential facet of the support for educational innovation, requiring interaction from both management and faculty.

\section{Conclusion}

Nurturing innovation within the spaces of the modern university is both an increasing necessity to the competitiveness of HE, as well as notoriously difficult to achieve. It has been noted that a paradox exists between the need for, and the barriers to, educational innovation (Brown, 2015). However, overcoming the barriers and encouraging pedagogical creativity requires more than just an emphasis upon the individual educator. Innovation also demands a focus on the interaction between peers, the networks of support, and the spaces in which these emerge. This paper has made use of detailed observation through an interdisciplinary lens to uncover the otherwise hidden patterns of faculty interactions and uses of space. Within this dialogue emerges a picture of commonplace occurrences which would perhaps otherwise go unnoticed. However, as has been shown, it is these multiple sites of everyday interactions, chance encounters, and affordances — or lack thereof — of spaces, indoor, and out, which give rise to quality teaching and learning within our institutions.

As such, a number of concluding remarks can be made: Firstly, the everyday spaces made use of by participants in this study described innovation occurring across both formal and informal learning spaces within the university. This tapestry of interaction could be seen to provide support for creative approaches to teaching while offering interaction with faculty alongside opportunities to seek peer support. Secondly, the presence (or lack of) affordances in these spaces determined the extent to which individuals were likely to remain and interact with their peers. Thirdly, and closely related to the previous point, the observation that forum spaces 
exist on both the micro- and macro-scale across campuses is suggestive of the need to integrate and interlink these 'anchor spaces' in order to foster a greater overlap of routines and interactions. Doing so would encourage a varied pattern of working and importantly promote the so-called serendipitous encounters and layered transactions which are seen to be central to innovation cultures in HE (P. Jamieson, 2003; Lippman et al., 2005). Spaces are made social through their various uses, and many spaces require activating through the promotion of activities conducive to peer support and networking. Initiatives, such as education lunches, and other common room events can act to stimulate the social function of shared spaces (Dobbins, 2009).

Finally, it should be highlighted that while many initiatives are now gathering steam across the UK, as well as internationally, aimed at appealing to a broader cohort of students and providing 'satisfaction' with teaching, tensions exist between the priorities of institutions and those of individuals delivering and creating educational experiences for their students. The cultures which arise in these settings as well as the spaces and forums which enable activities and encounters are sometimes caught between conflicting concerns. Making space for cultures of creative educational innovation, which enables the spontaneous practices and serendipitous encounters emphasised by this paper, requires striking a delicate balance.

As the HE sector moves further toward a mass education model - with student satisfaction with teaching becoming a key metric for success of institutions - the need for insight into how to offer support for faculty through the design of spaces in which they work becomes increasingly apparent. It is clear that much attention in future will need to be focused on how faculty-led initiatives work in tandem with estates teams and institutional governance. This paper signposts further avenues for exploration of spaces of peer-learning and is an invitation to reimagine campus environments conducive to creative educational practice.

Acknowledgements We would like to thank the 2018 Exeter Education Incubator Fellows for their time and thoughts in contribution to this work. Furthermore, we are grateful for the collaboration opportunities made possible through the Exeter Arts and Culture fellowship, enabling the interdisciplinary approach adopted by this paper. Finally, we wish to sincerely thank the two anonymous reviewers who provided insightful comments on our work and whose suggestions greatly improved this paper.

Open Access This article is distributed under the terms of the Creative Commons Attribution 4.0 International License (http://creativecommons.org/licenses/by/4.0/), which permits unrestricted use, distribution, and reproduction in any medium, provided you give appropriate credit to the original author(s) and the source, provide a link to the Creative Commons license, and indicate if changes were made.

\section{References}

Ashwin, P. W. H. (2017). What is the Teaching Excellence Framework in the United Kingdom, and will it work? International higher education(88), 10-11

Aydin, D., \& Ter, U. (2008). Outdoor space quality: Case study of a university campus plaza. International Journal of Architectural Research: ArchNet-IJAR, 2(3), 189-203.

Beckers, R., Van der Voordt, T., and Dewulf. G. (2016). Learning space preferences of higher education students. Building and Environment, 104, 243-252.

Berger, D., \& Wild, C. (2016). The Teaching Excellence Framework: would you tell me, please, which way I ought to go from here. Higher Education Review, 48(3), 5-22.

Brennan, J., Ryan, S., Ranga, M., Broek, S., Durazzi, N., \& Kamphuis, B. (2014). Study on innovation in higher education: final report. Retrieved from Luxembourg

Brown, R. (2015). The Marketisation of Higher Education: Issues and Ironies. Retrieved from https://www.uwl. ac.uk/sites/default/files/Departments/Research/new_vistas/vol1_iss1/vol1_iss1_art1_23April2015.pdf 
Coady-Schaebitz, S. (2016). Beyond the red line: how are universities re-imagining cities and urban communities through their spatial development plans? The University of Northampton Waterside campus.

Coulson, S., Garforth, L., Payne, G., \& Wastell, E. (2017). Admissions, adaptations, and anxieties: Social class inside and outside the elite university. In Higher Education and Social Inequalities. Routledge, Abingdon.

Dobbins, K. (2009). Feeding innovation with learning lunches: contextualising academic innovation in higher education. Journal of Further and Higher Education, 33(4), 411-422.

Dyer, S. (2018). Education Incubator Fellows 2017-2018. Retrieved from https://www.exeter.ac.uk/teachingexcellence/educationincubator/incubatorfellows201718/

Enarson, H., \& Drucker, P. F. (1960). Innovation in higher education. The Journal of Higher Education, 31(9), 495-501.

Gehl, J. (2011). Life between buildings: using public space: Island Press

Gehl, J. (2013). Cities for people: Island press

Gehl, J., \& Gemzøe, L. (2004). Public spaces-public life

Gehl, J., \& Svarre, B. (2013). How to study public life: Island Press

Gosling, D., \& Hannan, A. (2007). Responses to a policy initiative: the case of Centres for Excellence in Teaching and Learning. Studies in Higher Education, 32(5), 633-646.

Griffith, J. C. (1994). Open space preservation: An imperative for quality campus environments. The Journal of Higher Education, 65(6), 645-669.

Gunn, A. (2018). Metrics and methodologies for measuring teaching quality in higher education: developing the Teaching Excellence Framework (TEF). Educational Review, 1-20.

Hadgraft, R. and J. Dane (2014). Spaces for Engaging, Experiential, Collaborative Learning in Higher Education. The Future of Learning and Teaching in Next Generation Learning Spaces, Emerald, Bingley UK: 101-122.

Hannan, A., \& Silver, H. (2000). Innovating in Higher Education: Teaching. Learning and Institutional Cultures: ERIC.

Hasanefendic, S., Birkholz, J. M., Horta, H., \& van der Sijde, P. (2017). Individuals in action: bringing about innovation in higher education. European Journal of Higher Education, 7(2), 101-119.

Jacobs, J. (1961). The death and life of American cities

Jamieson, D. (2008). Ethics and the environment: An introduction: Cambridge University Press.

Jamieson, P. (2003). Designing more effective on-campus teaching and learning spaces: A role for academic developers. International Journal for Academic Development, 8(1-2), 119-133.

Klein, K. J., \& Sorra, J. S. (1996). The challenge of innovation implementation. Academy of Management Review, 21(4), 1055-1080.

Lindquist, J. (1974). Political linkage: The academic-innovation process. The Journal of Higher Education, 45(5), 323-343.

Lippman, P., Jamieson, P., \& Dane, J. (2005). Moving beyond the classroom: Accommodating the changing pedagogy of higher education. Paper presented at the Refereed Forum Proceedings of the Australian Association for Institutional Research

Macdonald, C., \& Stratta, E. (2001). From access to widening participation: responses to the changing population in higher education in the UK. Journal of Further and Higher Education, 25(2), 249-258.

Magdaniel, C. (2016). Technology campuses and cities : A study on the relation between innovation and the built environment at the urban area level. Architecture and the Built Environment. Online, Delft University of Technology. Doctorate.

Perec, G. (2010). An attempt at exhausting a place in Paris: Wakefield Press

Wenger, E. (1998). Communities of practice: Learning, meaning, and identity: Cambridge university press

Wenger, E., McDermott, R. A., \& Snyder, W. (2002). Cultivating communities of practice: A guide to managing knowledge: Harvard Business Press

Publisher's note Springer Nature remains neutral with regard to jurisdictional claims in published maps and institutional affiliations. 